\title{
INOVAÇÃO E INTEGRAÇÃO DAS TECNOLOGIAS DIGITAIS NA DOCÊNCIA UNIVERSITÁRIA: CONCEITOS E RELAÇÕES
}

\author{
Martha Prata-Linhares ${ }^{1}$ \\ Rogério Dias de Arruda $^{2}$
}

\begin{abstract}
Resumo
O objetivo deste artigo é discutir a incorporação das tecnologias digitais nas salas de aula na educação superior. Estudos nacionais e internacionais apontam que, apesar dos altos investimentos das políticas públicas, integrar as tecnologias digitais na docência ainda é uma tarefa difícil. Apresentamos uma pesquisa bibliográfica sobre o conceito de inovação e suas relações com as tecnologias digitais. Trazemos dados de pesquisas para discutir sobre a importância do desenvolvimento profissional docente e das políticas institucionais na educação superior. Citamos e discutimos as falas de docentes mexicanos, espanhóis e brasileiros sobre a integração das tecnologias digitais em suas práticas pedagógicas. $\mathrm{O}$ referencial teórico baseia-se principalmente em autores latino-americanos, anglo-saxônicos e espanhóis. O estudo ressalta que promover a inovação e a integração das tecnologias digitais nas práticas de ensino é um processo complexo, pois envolve, entre outros aspectos, os relacionados a questões pessoais e subjetivas, e também institucionais.
\end{abstract}

Palavras-chave: Educação Superior; Tecnologias de Informação e Comunicação; Prática Pedagógica

\section{INNOVATION AND DIGITAL TECHNOLOGIES INTEGRATION IN UNIVERSITY TEACHING: CONCEPTS AND RELATION}

\footnotetext{
${ }^{1}$ Doutora em Educação pela Pontifícia Universidade Católica de São Paulo- PUC/SP. Professora do Programa de Pós-graduação em Educação da Universidade Federal do Triângulo Mineiro- PPGE/UFTM. Av. Getúlio Guaritá, 159, Centro Educacional, sala 326 B - Bairro Abadia. CEP:38025-440 Uberaba/MG. Endereço eletrônico: martha.prata@gmail.com

${ }^{2}$ Doutor em Educação Ambiental pela Universidade Federal do Rio Grande- FURG. Pesquisador Pós-doutorando do Programa de Pós-graduação em Educação da Universidade Federal do Triângulo Mineiro- PPGE/UFTM. Av. Getúlio Guaritá, 159, Centro Educacional, sala 326 B - Bairro Abadia. CEP:38025-440 Uberaba/MG. Endereço eletrônico:rogerio.arruda@hotmail.com
}

Revista Reflexão e Ação, Santa Cruz do Sul, v. 25, n. 2, p. 250-268, Maio./Ago. 2017.

http://online.unisc.br/seer/index.php/reflex/index 


\begin{abstract}
The purpose of this article is to discuss the digital technologies incorporation in higher education classrooms. National and international studies show that, despite the high investments in public policies, integrating digital technologies into teaching is still a difficult task. A review of the literature on the concept of innovation and its relationship with digital technologies is presented. Some research data are presented with the objective of analyzing the importance of professional teacher development and institutional policies in higher education. The opinions of Mexican, Spanish and Brazilian teachers on the integration of digital technologies in their teaching practices are mentioned and discussed. The theoretical framework is based mainly on Latin American, Anglo-Saxon and Spanish authors. The study points out that promoting innovation and the integration of digital technologies into teaching practices is a complex process, since it involves, among other aspects, those related to personal and subjective issues, as well as institutional ones.
\end{abstract}

Keywords: High Education; Information and Communication Technologies; Pedagogical Practice

\title{
INNOVACIÓN Y INTEGRACIÓN DE TECNOLOGÍAS DIGITALES EN LA ENSEÑANZA UNIVERSITARIA: CONCEPTOS Y RELACIÓN
}

\section{Resumen}

El propósito de este artículo es discutir la incorporación de tecnologías digitales en las aulas de la educación superior. Estudios nacionales e internacionales muestran que, a pesar de las altas inversiones de orden público, la integración de las tecnologías digitales en la docencia sigue siendo una tarea difícil. Se presenta una revisión de la literatura sobre el concepto de innovación y su relación con las tecnologías digitales. Algunos datos de investigaciones son presentados con el objetivo de analizar la importancia de desarrollo profesional docente y las políticas institucionales en la educación superior. Son mencionadas e discutidas las opiniones de docentes mexicanos, españoles y brasileños sobre la integración de las tecnologías digitales en sus prácticas de enseñanza. El marco teórico se basa principalmente en autores latinoamericanos, anglosajones y españoles. El estudio señala que la promoción de la innovación y la integración de las tecnologías 
digitales en las prácticas de enseñanza es un proceso complejo, ya que implica, entre otras cosas, la relación con aspectos personales, subjetivos e institucionales.

Palavras-clave: Educación Superior; Tecnología de La Información y La Comunicación; Práctica Docente

\section{INTRODUÇÃO}

A Conferência Mundial de Educação Superior (CMES), realizada em Paris, em julho de 2009, estabeleceu que a universidade é um bem público e não uma mercadoria. De acordo com Ristoff (2013), estabeleceu também que a universidade, com seus mestrados e doutorados, com o ensino e a extensão tem um papel de protagonista na sustentabilidade da vida no planeta.

O relatório final da CMES menciona que nunca antes na nossa história foi tão importante investir na Educação Superior como "força maior na construção de uma sociedade inclusiva e de conhecimento diversificado, além de avançar em pesquisa, inovação e criatividade" (UNESCO, 2009, p.2). No documento, as Tecnologias da Informação e Comunicação (TIC) são apresentadas com potencial para aumentar o acesso, a qualidade e o sucesso no ensino e na aprendizagem das pessoas. Menciona-se também a importância de novas abordagens com a presença das TIC nos currículos e nos programas de formação inicial e continuada de professores. Por fim, há um convite à ação de apoio à integração total das TIC na educação superior.

Mais recentemente, na agenda de desenvolvimento para a educação e no Position Paperon Education Post-2015 (UNESCO, 2014), as TIC são retomadas e é mencionada a necessidade de aumentarmos e flexibilizarmos as oportunidades de aprendizagem tanto em espaços formais como não formais, bem como o potencial que as tecnologias digitais têm para contribuir com esse item. Também é chamada a atenção para a formação de professores a fim de fortalecer as "capacidades para os alunos serem inovadores e criativos e, para assimilar mudanças em sua sociedade" (UNESCO, 2014, p. 8). Porém, é interessante observar que estudos nacionais e internacionais, como comenta Garcia (2015), apontam que a incorporação das tecnologias digitais nas salas de aula não tem sido tarefa fácil, apesar dos altos investimentos nas políticas públicas ao redor do planeta.

Ao reportar uma pesquisa internacional realizada com professores e com diretores de escolas sobre ensinar e aprender, o relatório Teaching and Learning International Survey Revista Reflexão e Ação, Santa Cruz do Sul, v. 25, n. 2, p. 250-268, Maio./Ago. 2017. http://online.unisc.br/seer/index.php/reflex/index 
TALIS (OECD, 2014) assinalou que as habilidades para usar tecnologias digitais nas escolas e para promover aprendizagem ainda têm sido um desafio para grande parte desses profissionais que, apesar de reconhecerem a importância de explorarem as tecnologias digitais nos espaços de aprendizagem, continuam não se sentindo preparados. A justificativa é que isso se deve, em parte, por ser um processo que demanda mudanças contínuas, já que os aparatos tecnológicos estão em constantes modificações.

Para discutir essa temática, estruturamos o artigo em quatro seções: a primeira apresenta o conceito de inovação e suas relações com as tecnologias digitais; a segunda seção apresenta dados de algumas pesquisas que permitem a discussão sobre a importância do desenvolvimento profissional docente e das políticas institucionais; a terceira apresenta e discute as opiniões de docentes mexicanos, espanhóis e brasileiros sobre a integração das tecnologias digitais em suas práticas pedagógicas; e, por fim, a quarta seção apresenta as considerações finais.

\section{CONCEITO DE INOVAÇÃO E SUAS RELAÇÕES COM AS TECNOLOGIAS DIGITAIS}

A integração das TIC, das tecnologias digitais, associada à motivação para seu uso na prática pedagógica pode se constituir em um dos fatores para desencadear uma prática inovadora. Mas, como se sabe, uma prática inovadora envolve outros aspectos.

Uma revisão na literatura sobre este tema mostrou que os novos estudos têm apresentado abordagens mais densas sobre os processos que envolvem a inovação, bem como sobre o uso das TIC e das tecnologias digitais nas práticas pedagógicas, evidenciando o crescente número de fatores que influenciam diretamente esses processos, ou seja, torna-se imprescindível considerar, numa análise atual sobre essa temática, ao menos, os seguintes aspectos: a) geográficos (localização da instituição - país, estado, cidade); b) institucionais (estrutura, organização, cultura e política educativa da instituição); c) pessoais (a própria formação docente, crenças teóricas sobre o ensino e a aprendizagem, postura sobre o uso das TIC em sua prática pedagógica, motivações e outros.); e d) instrumentais (no que diz respeito aos avanços das potencialidades e aplicabilidades dos recursos tecnológicos).

Nesse sentido, as noções sobre o conceito de inovação também incorporam novos aspectos advindos dessas discussões mais profundas, que é o que passamos a explanar. No entanto, até para se ter uma dimensão da evolução dessas novas abordagens, essa explanação inicia com um conceito considerado clássico, no qual Rogers (1962) considera a inovação Revista Reflexão e Ação, Santa Cruz do Sul, v. 25, n. 2, p. 250-268, Maio./Ago. 2017.

http://online.unisc.br/seer/index.php/reflex/index 
como uma ideia, uma prática ou um objeto que é percebido como novo por um indivíduo. Pode-se considerar essa definição como um ponto de partida, mas que, obviamente, já não consegue dar conta das novas situações em que a inovação está presente nas práticas pedagógicas.

Assim, agora trazendo novas incorporações às ideias primeiras de Rogers, uma noção mais descritiva, apresentada por Figueiredo (2011) e Christensen (2012), faz referência a dois tipos principais de inovação: a incremental (ou sustentada) e a disruptiva. Sobre a inovação incremental, diz Figueiredo (2011) que sua base está em introduzir melhoramentos em produtos, processos, organizações ou sistemas sociais já existentes. Com relação à inovação disruptiva, Christensen (2012) aponta para o fato de elas emergirem de forma exploratória, sendo que as maiores oportunidades para inovar não se encontram na tentativa de melhorar o que já existe, mas de criar soluções para necessidades ainda não satisfeitas.

Em outros estudos consultados, como os realizados por Martínez; Correa (2010), Aceto, Dondi; Marzotto (2010) e Gallego (2005), o conceito de inovação está atrelado a questões que envolvem a melhora e o alcance da aprendizagem. Para esses autores, a inovação faz-se presente quando oportuniza que a aprendizagem (apoiada pelas TIC e tecnologias digitais) saia dos muros das instituições educacionais, possibilitando conexões significativas com a realidade externa à instituição educacional, provocando efeitos positivos na formação dos alunos. Isso também encontra eco nas noções defendidas por Sancho et al. (2015) e Rubia (2010), que acrescentam que essa formação deve preparar, para além de alunos, cidadãos responsáveis, solidários e dinâmicos, aptos a fazer uma "leitura de mundo" mais ampla, preparados para se adaptar a novas situações e promover a criatividade e qualidade pessoal e social.

Ainda nesta vertente de ampliar os horizontes para além dos muros das instituições de educação, Montero; Gewerc (2010) e Reis (2013) expressam que a inovação tem como característica a ideia de mudar algo, mas que essa mudança deve se converter numa proposta intencional da instituição de educação, que considere a comunidade na qual está inserida, com a intenção de dar respostas às suas necessidades reais, internas, e também de seu entorno. A essa noção se somam os estudos de Roig (2008) e Dulac; Aleonada (2008), que acrescentam que uma proposta assim também deve avançar nos conceitos, técnicas, atitudes e valores, visando à melhora da condição humana, em atitude crítica e solidária, buscando o bem comum.

Por outro lado, existem estudos em que há a vinculação da noção de inovação com as estratégias adotadas para ensinar os alunos. Orozco (2007) e Muñoz-Cano; Córdova; Priego Revista Reflexão e Ação, Santa Cruz do Sul, v. 25, n. 2, p. 250-268, Maio./Ago. 2017.

http://online.unisc.br/seer/index.php/reflex/index 
(2012), por exemplo, opinam que a inovação é complexa, integrando vários elementos, entre os quais a necessidade de se pensar estratégias que permitam aos sujeitos familiarizarem-se com a própria inovação, facilitando, dessa maneira, o desenvolvimento de competências cognitivas de alto nível. Isso devido ao fato de que há professores que, mesmo com o uso de recursos digitais, reproduzem práticas pedagógicas tradicionais. Trata-se, portanto, de um processo de "negociação" com esses professores, no intuito de oportunizar que consigam superar tais práticas construindo formatos realmente inovadores. Sobre essa "negociação", Marcelo, Yot; Mayor (2015a) destacam que os professores que se sentem motivados a introduzir as tecnologias em suas práticas pedagógicas procuram fazê-lo de maneira coerente com suas crenças sobre o uso das tecnologias digitais, mas atentando para não perder a estabilidade que já construíram em suas trajetórias profissionais.

Outros estudos defendem que a noção do conceito de inovação está relacionada com a integração das TIC e das tecnologias digitais no currículo. Alves et al. (2011) comentam que a adoção de práticas pedagógicas inovadoras tem por base um paradigma de ensinoaprendizagem que faça da flexibilização curricular, do desenvolvimento de competências e da articulação curricular suas principais fortalezas. Prata-Linhares; Masetto (2013) destacam a necessidade de promover transformações curriculares para transpor os limites impostos por currículos tradicionais e, assim, avançar nas práticas pedagógicas inovadoras. Salinas (2009) explica que, além de mudanças no currículo, a inovação também implica mudanças nas formas de ver, pensar, organizar e articular as disciplinas. Isso exige que as instituições promovam um processo de reflexão sobre os procedimentos ali adotados, bem como sobre suas estruturas administrativas, no sentido de promover adaptações e adequações às novas modalidades de formação que a sociedade requer, como, por exemplo, a educação a distância.

Tejada (2008) e Losada (2010) também concordam que a inovação requer mudanças nos elementos curriculares, no sentido de que tais mudanças devem ser baseadas num objetivo comum e orientadas à melhora e crescimento, tanto pessoal quanto institucional. Além disso, defendem mudanças - internas e qualitativas - também nos processos educativos e em seus contextos mais imediatos, com critérios objetivos.

Garcia (2013), ao falar das universidades, chama a atenção para o fato de elas estarem sendo alvo, para o bem e para o mal, de uma sociedade que espera que os sistemas educativos contribuam de fato para a promoção de cidadãos educados para o século XXI. Mas, o autor explica que parece que estamos vivendo uma época em que "temos escolas do século XIX, com docentes do século XX, para alunos do século XXI" (GARCIA, 2013, p. 27, tradução nossa). Ainda esclarece que a literatura tem mostrado que nos processos de mudança as Revista Reflexão e Ação, Santa Cruz do Sul, v. 25, n. 2, p. 250-268, Maio./Ago. 2017.

http://online.unisc.br/seer/index.php/reflex/index 
inovações podem surgir com facilidade dentro e fora das instituições de educação, mas que são ameaçadas por fatores como a falta de recursos, desilusão, falta de reconhecimento e crises internas e externas das equipes de trabalho. Por fim, para o autor a inovação é um conceito e também um processo. E, para que os projetos inovadores sejam sustentáveis e a instituição de ensino continue sendo um espaço de inovação com TIC é necessário haver uma renovação do compromisso com a qualidade da aprendizagem dos alunos que se traduz em rever "tanto os conteúdos curriculares que configuram o currículo escolar como os próprios processos de ensino e aprendizagem vigente em nossas escolas e institutos. E isso supõe um sério trabalho para os professores como profissionais da educação" (GARCIA, 2013, p. 45, tradução nossa).

Outra vertente encontrada na revisão de literatura relaciona a noção de inovação ao desejo pessoal e às relações entre professor e aluno. Martínez (2008) comenta sobre os anseios e questionamentos pessoais, na perspectiva de que o desejo e a atitude devem mover os professores a tentar melhorar (e inovar) suas práticas pedagógicas no intuito de oferecer uma melhor educação para seus alunos. Correa (2010) vincula o conceito de inovação às relações entre professor e aluno e entre eles e a construção do conhecimento no processo educativo, argumentando que a inovação pedagógica não acontece pelo simples fato de se passar a usar as tecnologias digitais em salas de aula. Além disso, Correa et al. (2015) mencionam que é imperioso para a inovação educativa o questionamento sobre o naturalizado, a reflexão por parte dos sujeitos do processo de ensino-aprendizagem, o que permite repensar os desafios e construir outro olhar sobre a realidade.

Para Melaré et al. (2011), não se pode esquecer a presença da inovação com o uso das TIC e das tecnologias digitais, na dinâmica do trabalho colaborativo em rede, que propicia aos processos de educação e formação novas metodologias de aprendizagem colaborativa, com impacto no desenvolvimento de processos de interação. As redes sociais e suas novas dinâmicas, por exemplo, representam um potencial pedagógico que precisa ser mais investigado.

Finalizando o panorama das noções sobre o conceito de inovação, fazemos uso das ideias de Paredes; Guitert; Rubia (2015, p. 111, tradução nossa) que observam alguns aspectos que podem efetivamente contribuir para a inovação na prática pedagógica e no processo educativo:

A inovação educativa deve estar atenta a todas as formas de organização e usos transformadores com as TIC, devendo analisá-las cuidadosamente e reinterpretá-las, experimentá-las, potencializá-las e propor outras novas. A transformação começa

Revista Reflexão e Ação, Santa Cruz do Sul, v. 25, n. 2, p. 250-268, Maio./Ago. 2017.

http://online.unisc.br/seer/index.php/reflex/index 
em espaços insuspeitáveis entre educadores que procuram respostas a seus problemas. A formação deve estar aberta às soluções dos grupos de educadores, às pesquisas, aos movimentos sociais e às empresas. Qualquer projeto, associação ou colaboração pode oferecer opções para formação sobre inovação com TIC. Sugerimos aprofundar experiências que potencializem outra relação com o conhecimento, o inter e o transdisciplinar, a vivência de um currículo não convencional, a atenção com os problemas cotidianos, a revalorização da cultura, o uso do tempo e do espaço, o papel da comunidade, a atividade dos estudantes e de suas famílias, a colaboração entre estudantes, professores e escolas; a potencialização do pessoal, do afetivo e do criativo, bem como da orientação aos estudantes e da personalização das experiências de aprendizagem, da coavaliação e outras modalidades avaliativas.

\section{PEDAGOGIAS DO TRABALHO COM TECNOLOGIAS DIGITAIS: A IMPORTÂNCIA DO DESENVOLVIMENTO PROFISSIONAL DOCENTE E DAS POLÍTICAS INSTITUCIONAIS}

Outra questão importante e que não podemos deixar de citar é a dicotomia entre teoria e prática. Autores como Veiga (2010), Soares; Vieira (2014), Masetto; Gaeta (2015) e Craig; Orland-Barak (2015), dentre outros, têm afirmado que a divisão teoria-prática ainda se manifesta na educação, em geral, e na formação de professores. É um desafio perene que os educadores vivem e está presente em histórias que professores de diferentes países contam sobre suas vidas. É, portanto, uma dificuldade internacional, ainda a ser transposta por vários países. Pensamos, então, que unir teoria e prática talvez seja uma mudança e, por que não dizer, uma inovação necessária que tem provocado professores ao redor do planeta.

Como já dissemos anteriormente, a incorporação das TIC nos currículos e nas salas de aula não tem sido tarefa fácil. Muitas vezes essas tecnologias acentuam a divisão entre teoria e prática, pois chegam aos estudantes justamente para colocar "em prática" ou "ilustrar" algum conceito específico e sem uma problematização e/ou contextualização.

Em pesquisa realizada junto a docentes de cursos de graduação em Administração e Ciências Contábeis de duas instituições de educação superior distintas, Vespasiano (2016) percebeu que, dos 47 professores entrevistados, 22 deles gostariam de saber criar conteúdos de multimídia e sítios na internet. A análise dos dados sugere que os professores pesquisados estão preocupados não só em consumir e usar a informação, mas também em criar e produzir informações digitais, inserindo-se assim na cultura digital. A mesma pesquisa também mostrou que esses professores universitários, apesar de dizerem que sabem da potencialidade das TIC para a aprendizagem de seus alunos, muitas vezes trazem essas tecnologias digitais para a sala de aula sem integrá-las em suas práticas pedagógicas, mas sim por se sentirem 
pressionados pelos alunos, no sentido de serem percebidos como professores que acompanham a atualidade.

Em outra pesquisa, os resultados apontados por Andrade (2016) sugerem que é necessário investir no desenvolvimento profissional do professor universitário para que as TIC cheguem às práticas pedagógicas não somente como um novo recurso a ser usado em sala de aula para ilustrar os conteúdos, como apontado em sua pesquisa ao analisar as entrevistas de 30 docentes graduados em engenharia. Na investigação, muitos professores comentam que preferem introduzir as tecnologias somente depois de demonstrar os cálculos para os alunos no quadro negro.

Ainda que sejam pesquisas pontuais, autores como Gaeta; Prata-Linhares (2013), Marcelo (2009), Masetto (2003) e Zabalza (2004), dentre outros, destacam a importância do investimento na formação de professores e no desenvolvimento profissional docente, confirmando que, atualmente, não basta que o professor domine o conteúdo a ser ministrado, domine as TIC e as técnicas a serem aplicadas, pois como afirmam as autoras Gaeta; PrataLinhares (2013, p. 346), faz parte da formação profissional específica do professor do Ensino Superior a formação inicial obtida na graduação e é necessária também a formação continuada ou permanente "por se tratar de um processo cujo propósito é desenvolver o indivíduo, proporcionando uma melhora profissional e humana que permita adequar-se às mudanças sociais, políticas, econômicas e científicas do mundo em que vive.” As autoras ainda complementam afirmando que "esse processo de desenvolvimento profissional pressupõe revisão, reflexão e mudança em dimensões como: cognitiva, pedagógica, teórica, pessoal e profissional” (GAETA; PRATA-LINHARES, 2013, p. 346).

Pensamos, assim, que é no e com o processo de formação e de desenvolvimento profissional docente que teremos oportunidades para ultrapassar essa dicotomia entre teoria e prática e promover a integração das tecnologias digitais na docência. A literatura internacional nos apresenta algumas experiências consideradas exitosas e inovadoras na Espanha (MARCELO; YOT, 2015b), Suíça (CHARLIER; COEN, 2015) e Noruega (HAUGE, 2015).

Na experiência da Espanha, Marcelo; Yot (2015b) trazem a perspectiva da integração das tecnologias ao conhecimento profissional dos professores tendo como referência o Technological Pedagogical Contente Knowledge (TPCK) - traduzido para Conhecimento Tecnológico e Pedagógico do Conteúdo (TPACK), de Koehler; Mishra (2008). O TPACK é o resultado da união de três conhecimentos: o Conhecimento Pedagógico de Conteúdo, o Conhecimento Tecnológico e Pedagógico e o Conhecimento Tecnológico de Conteúdo. 
De acordo com os autores, são vários os exemplos de "boas práticas" de incorporação das TIC em programas de desenvolvimento profissional docente. Em todas essas experiências o foco está em ultrapassar a visão tecnicista e trazer as tecnologias digitais para uma outra dimensão, um espaço em que haja um diálogo e uma integração entre o conhecimento tecnológico, conhecimento pedagógico e o conhecimento do conteúdo específico de cada área. De acordo com os autores, os esforços dos programas de desenvolvimento profissional deveriam se concentrar justamente na intersecção desses diferentes conhecimentos.

Os autores Charlie; Coen (2015), da Suíça, ressaltam a importância de cultivar nos programas de desenvolvimento profissional docente a literacia nas tecnologias digitais multimodais. Afirmam também que os alunos universitários, futuros professores, devem ser estimulados a integrar as tecnologias digitais em suas práticas pedagógicas e contribuir com as pesquisas nessa área.

Hauge (2015), da Noruega, salienta a importância de aspectos como parcerias entre instituições de educação superior com o que ele chama de "escolas de treinamento" para a legitimação do uso das tecnologias digitais na formação de professores, e ressalta que é necessário um árduo trabalho para desenvolver e manter as atividades e as relações sustentáveis entre as instituições.

As experiências relatadas por Charlie; Coen (2015), Hauge (2015) e Marcelo; Yot (2015b) estão inseridas em projetos que duram anos e que se modificam e melhoram com avaliações e com políticas institucionais de fomento em seus respectivos países.

Com relação às políticas institucionais brasileiras para o desenvolvimento profissional docente do professor universitário, ainda não temos, no Brasil, a tradição dos centros institucionais de desenvolvimento profissional docente, prática já consolidada em muitos países, como, por exemplo, Austrália, Canadá, Escócia, E.U.A., Jamaica e Oman. Porém, cabe mencionar que, em pesquisa realizada com pró-reitores de ensino em 36 instituições de educação superior federais brasileiras, 23 pró-reitores declararam já existir uma política institucional de formação continuada para os docentes da instituição (OLIVEIRA; PRATALINHARES; KARWOSKI, 2016). Isso nos leva a pensar que, com o tempo e com o fomento de pesquisas que mostrem a necessidade e a importância do investimento nessas ações, essas políticas deverão se desenvolver.

\section{O QUE DIZEM OS PROFESSORES MEXICANOS, ESPANHÓIS E BRASILEIROS}


A integração das tecnologias digitais no processo educativo vem desencadeando uma série de mudanças na prática docente que são acompanhadas por questionamentos, dificuldades e incertezas, mas também por novas oportunidades, entre elas, a de promover mudanças, inovações pedagógicas no processo de ensino-aprendizagem.

Contudo, o simples fato de passar a utilizar as tecnologias digitais em sua prática pedagógica não faz do docente um sujeito inovador, pois há outros fatores que também influenciam, sejam eles pessoais (a própria formação, concepções sobre ensino e aprendizagem, postura sobre as TIC, as relações, motivações e outros), institucionais (estrutura, organização e política da instituição), geográficos (localização da instituição) ou instrumentais (potencialidades e aplicabilidades dos recursos tecnológicos). Chamamos a atenção para o fato de a presença das tecnologias digitais poderem potencializar hábitos arraigados. As tecnologias digitais sem a educação, conhecimentos e sabedoria que permitam organizar o seu real aproveitamento, levam-nos apenas a fazer mais rápido e em maior escala os mesmos erros. Nesse sentido, há bastante tempo, Dowdor (2001), ao se referir ao advento das tecnologias digitais, já alertava que as bobagens poderiam ser feitas em maior volume e com muito mais rapidez.

Além disso, as inovações pedagógicas também estão em uma estreita relação com as estratégias didáticas adotadas na prática docente, bem como com a criatividade para criá-las e para executá-las, se assim o currículo permitir.

Nessa perspectiva, apresentamos a seguir as opiniões de alguns professores mexicanos, espanhóis e brasileiros, de cursos de licenciatura, que foram entrevistados e convidados a falar sobre sua prática pedagógica, e que revelam aspectos que fazem referência a essa relação entre a prática pedagógica com tecnologias digitais, a inovação e o currículo. Tais opiniões consistem num recorte que fizemos da pesquisa em andamento que tem como objetivo compreender as inovações e mudanças pedagógicas que estão acontecendo na prática docente com o uso das tecnologias digitais em cursos de graduação no México, Espanha e Brasil ${ }^{3}$.

Para manter o sigilo, os nomes dos participantes serão identificados por códigos que foram atribuídos de forma aleatória. Os códigos são os seguintes:

- Códigos para os docentes mexicanos: DM1 a DM10

- Códigos para os docentes brasileiros: DB1 a DB9

- Códigos para os docentes espanhóis: DE1 a DE8

\footnotetext{
${ }^{3}$ Esta pesquisa é desenvolvida no Programa de Pós-graduação em Educação da Universidade Federal do Triângulo Mineiro - UFTM, e recebe apoio financeiro da Coordenação de Aperfeiçoamento de Pessoal de Nível Superior (CAPES), do Brasil.
}

Revista Reflexão e Ação, Santa Cruz do Sul, v. 25, n. 2, p. 250-268, Maio./Ago. 2017.

http://online.unisc.br/seer/index.php/reflex/index 
Começamos com a opinião de um docente do México (DM9), que diz:

a inovação que tenho alcançado após integrar as tecnologias digitais nas aulas de diversas formas é a 'pedagogia inversa', com a finalidade de alcançar a aprendizagem autorregulada. (DM9, tradução nossa).

Esse participante relata que tem conseguido resultados inovadores com o uso das tecnologias digitais, fazendo referência à "sala de aula invertida" (ou flipped classroom), que, resumidamente, pode ser entendida como um método que visa a alterar o modelo do ensino presencial, mudando sua lógica de organização tradicional. $\mathrm{O}$ aluno tem acesso ao material da disciplina com antecedência para discutir o conteúdo com os colegas e o professor na sala de aula, que se torna um espaço dinâmico e interativo, à medida que pode estimular debates a partir de vários posicionamentos. Tudo com o auxílio de recursos tecnológicos. Essa prática pode ser relacionada à noção de inovação mencionada por Orozco (2007) e Muñoz-Cano, Córdova; Priego (2012), no sentido de se pensar novas estratégias para o processo de ensino que permitam o desenvolvimento de competências cognitivas, e também, conforme Salinas (2009), quando implica mudanças no currículo e na forma de pensar e organizar as disciplinas.

Um docente da Espanha (DE2) assim se expressa:

A criatividade deve ter um papel essencial, mas nem sempre é a realidade das aulas universitárias. Ainda há muitas aulas tradicionais que se limitam a transmitir informações, conhecimentos estereotipados, com muitas diferenças entre especialidades. Há desequilíbrios, o desenvolvimento não é homogêneo. (DE2, tradução nossa).

Nessa manifestação, o participante concorda com a importância da criatividade, mas ressalta que a presença dela no processo de ensino não é uma prática corrente, havendo o predomínio de aulas tradicionais.

Na opinião de um docente brasileiro (DB5):

Infelizmente, a criatividade na docência no ensino superior é consideravelmente limitada, predominando nas atividades de pesquisa. Isto é, pouco se discute e menos ainda procura-se incorporar a criatividade na prática docente. As disciplinas de 
física, matemática e química praticamente se resumem a discussões teóricas, seguidas de "confirmações", ainda sustentadas em um positivismo disfarçado pelas roupagens $e$ linguagens mais contemporâneas. A aprendizagem, se assim pode ser chamada, resume-se a memorizar e reproduzir conhecimentos nas provas, que acabam por ser parte das listas de exercícios. [...] Ainda tentamos fazer algumas atividades de elaborar materiais $e$ utilizar estratégias de ensino mais discutidas na área de pesquisa, valorizando a criatividade. Mas com a ausência de flexibilidade curricular, com forte segmentação entre as disciplinas de educação, de ensino, de conteúdo específico e de ciências humanas, com a ausência de disciplinas que valorizem as artes e a literatura, muito pouco de abertura para criar. Há pouco ou nenhum espaço para explorar a criatividade, sobretudo, por uma compactação do currículo, cheio de conteúdos específicos e praticamente ausente de discussões sociológicas, filosóficas, artísticas e sobre as ciências. Muito poucos conseguem, um ou dois docentes que procuram adotar estratégias que fogem à memorização e à reprodução mecânica do conteúdo. A esse respeito, conseguir desencadear discussões sobre educação já é um avanço, mas longe de permitir o efetivo desenvolvimento de atividades criativas.

Identifica-se nesse relato uma espécie de "desabafo" sobre as condições às quais se submetem alguns docentes em suas práticas (seria um traço de determinada área do conhecimento?). É possível perceber um posicionamento que confere grande importância à criatividade, presente nas atividades de pesquisa, mas, segundo esse participante, com uma dificuldade imensa de ser desenvolvida no ensino, em grande medida, por um currículo “engessado" que não permite flexibilizações. Há, inclusive, a menção ao uso disfarçado de "roupagens e linguagens mais contemporâneas" (que podem ser as tecnologias digitais), mas reforçando um enfoque tradicional (MORAN, 2008; PAREDES, 2009), ou seja, não há um uso ressignificado, mas sim reprodutor de práticas positivistas. Porém, no que tange à criatividade em si, o aspecto que mais chama a atenção é que, segundo ele, "pouco se discute e menos ainda procura-se incorporar a criatividade na prática docente”, algo que realmente não favorece as transformações tão necessárias para o avanço da educação.

O relato de outro docente espanhol (DE8) segue nesta mesma direção. Ele diz que:

Considero que a criatividade é necessária para inovar nas práticas docentes. Lamentavelmente, o ensino universitário é muito fragmentado. As experiências docentes não são compartilhadas.

Revista Reflexão e Ação, Santa Cruz do Sul, v. 25, n. 2, p. 250-268, Maio./Ago. 2017.

http://online.unisc.br/seer/index.php/reflex/index 
Portanto, não conheço o ensino de outros professores para dar opinião sobre o grau de inovação. No entanto, em termos gerais, considero que a criatividade é condição necessária para inovar. (DE8, tradução nossa).

Da mesma forma que nas três opiniões anteriores, esse participante também considera a importância da criatividade na prática docente, inclusive expressando que se trata de uma condição fundamental para que haja a inovação. Contudo, lamenta a fragmentação do ensino, que impede a troca de experiências.

Essas quatro opiniões convergem com outras, que destacam a importância da criatividade no processo educativo. Porém, expressam a dificuldade de perceber sua presença nas situações de ensino que vivenciam, por vários motivos (aulas tradicionais, currículo "fechado", ausência de debate, e outros).

\section{CONSIDERAÇÕES FINAIS}

Os avanços tecnológicos têm proporcionado grandes mudanças na sociedade e a palavra inovação tem sido uma presença constante nos discursos das políticas públicas nacionais e internacionais. Ao mesmo tempo, já sabemos que os avanços tecnológicos não necessariamente trazem inovações para a educação nas instituições de ensino.

A pesquisa bibliográfica que realizamos mostrou que o conceito de inovação na educação não é simples e está relacionado a mudanças, à criação de soluções para necessidades não satisfeitas, a estratégias para lidar com a própria inovação e à integração das tecnologias digitais. Mas, tanto a inovação como a integração das tecnologias digitais têm relação com a complexidade das crenças, desejos e motivações presentes nos professores.

Nas falas dos professores, a importância da criatividade é ressaltada. Porém, o professor brasileiro chama a atenção para o fato de que a criatividade está presente nas pesquisas, mas não na docência.

Pensamos que as ideias e apontamentos que trouxemos neste artigo podem contribuir tanto para a reflexão sobre a necessidade de se pensar e investir nos espaços e na formação do docente universitário, como dar subsídios para como promover essa formação com vistas ao desenvolvimento da inovação nos processos educativos e na flexibilidade de oportunidades de aprendizagens nas instituições de educação superior para docentes e discentes.

\section{REFERÊNCIAS}


ACETO, S.; DONDI, C.; MARZOTTO, P. Pedagogical innovation in new learning communities. European Commission JRC Scientific and Technical Reports, 2010. Disponível em: <http://ftp.jrc.es/EURdoc/JRC59474.pdf>.

ALVES, Maria. P. et al. Práticas inovadoras no ensino superior. Braga: Instituto de Educação, Universidade do Minho, 2012. Disponível em: <http://hdl.handle.net/1822/23121>.

ANDRADE, Neusa A. G. Docência nos cursos engenharia e a utilização das TIC: em foco o desenvolvimento profissional docente. 2016. 150f. Dissertação (Mestrado em Educação) Universidade Federal do Triângulo Mineiro, Uberaba.

CHARLIE, Bernadette; COEN, Pierre-François, Pedagogies of Working with Technology in Switzerland, In: ORLAND-BARAK, Lily; CRAIG, Craig (ed.). International Teacher Education: Promising Pedagogies (Part B) (Advances in Research on Teaching, Volume 22B) Emerald Group Publishing Limited, p.401 - 414, 2015.

CHRISTENSEN, C. M.; HORN, M. B.; JOHNSON, C. W. Inovação na sala de aula: como a inovação disruptiva muda a forma de aprender. Tradução de Rodrigo Sardemberg. Porto Alegre: Bookman, 2012.

CORREA, J. M. Buenas prácticas con tecnología en los procesos de enseñanza y aprendizaje. In: CORREA, J. M. (coord.). Políticas educativas TIC en el País Vasco y buenas prácticas de enseñanza y aprendizaje. Madrid: Ediciones Paraninfo, 2010. p. 39-51.

CORREA, J. M. et al. Formación del Profesorado, Tecnología Educativa e Identidad Docente Digital. RELATEC - Revista Latinoamericana de Tecnología Educativa, Cárceres, v. 14, n.1, p. 45-56, 2015.

CRAIG, C.; ORLAND-BARAK, L. International Teacher Education: Promising Pedagogies Introduction. In: ORLAND-BARAK, L.; CRAIG, C. (ed.). International Teacher Education: Promising Pedagogies - part B. Advances in Research on Teaching, Emerald Group Publishing Limited, v 22b, 2015. p. 1-5.

DULAC, J.; ALEONADA, C. Innovación educativa y el uso de las tecnologías pizarra digital interactiva. In: AMARAL, S.; GARCÍA, F.; MEDINA, A. Aplicaciones educativas y nuevos lenguajes de las TIC. Campinas: Graf. FE, 2008. p. 125-135.

FIGUEIREDO, A. D. Inovar em Educação, Educar para a Inovação. In: FERNANDES, D. (Org.), Avaliação em educação: olhares sobre uma prática social incontornável. Pinhais: Editora Melo, 2011. p. 13-28.

GAETA, C.; PRATA-LINHARES, M. M. Pós-graduação lato-sensu: um espaço privilegiado para a formação docente no ensino superior. Olhar de Professor, Ponta Grossa, v.16, n.2, p. 343-356, fev. 2013. Disponível em: <http://www.revistas2.uepg.br/index.php/olhardeprofessor/article/view/6358/4421>.

GALLEGO, M. J. Profesorado, innovación y TIC en el currículo. In: CEBRIÁN, M. (coord.). Tecnologías de la Información y Comunicación para la formación de docentes. Madrid: Ediciones Pirámide, 2005. p. 159-170. 
HAUGE, Trond E. Preparing Teachers for Tomorrow's Schools: Reforming Initial Teacher Education with the Use of ICT in Norway. In: ORLAND-BARAK, L.; CRAIG, C. (ed.). International Teacher Education: Promising Pedagogies - part B. Advances in Research on Teaching, Emerald Group Publishing Limited, v. 22b, 2015. p.415 - 437.

LOSADA, Daniel. Marco estratégico de Euskadi ante la Sociedad de la Información en la Escuela. In CORREA, J. M. (coord.). Políticas educativas TIC en el País Vasco y buenas prácticas de enseñanza y aprendizaje. Madrid: Ediciones Paraninfo, 2010. p. 1-18.

MARCELO, C.; YOT, C.; MAYOR, C. Enseñar con tecnologías digitales en la Universidad. Revista Comunicar, v. XXIII, n. 45, 2015a. p. 117-124. https://doi.org/10.3916/C45-2015-12

MARCELO, C.; YOT, C. Pedagogies of Working with Technology in Spain, In: ORLANDBARAK, L.; CRAIG, C. (ed.). International Teacher Education: Promising Pedagogies - part B. Advances in Research on Teaching, Emerald Group Publishing Limited, v. 22b, 2015b. p. 329-357.

MARCELO, Carlos. Las tecnologías para la innovación y la práctica docente. Revista Brasileira de Educação, Rio de Janeiro, v. 18, n. 52, p. 25-47, mar. 2013.

Desenvolvimento Profissional Docente: passado e futuro. Sísifo - Revista de Ciências da Educação, Sevilha, v. 8, p. 7-22, 2009. Disponível em:

<http://sisifo.fpce.ul.pt/pdfs/S8_PTG_CarlosMarcelo20(1).pdf>.

MARTÍNEZ, A.; CORREA, J. M. Innovación y cambio fuera y dentro de la escuela. In: CORREA, J. M. (coord.). Políticas educativas TIC en el País Vasco y buenas prácticas de enseñanza y aprendizaje. Madrid: Ediciones Paraninfo, 2010. p. 29-38.

MARTÍNEZ, J. Pero ¿Qué es la innovación educativa? In: Cuadernos de Pedagogía. n. 375, p. 78-82, jan. 2008.

MASETTO, M.; GAETA, C. Os desafios para a formação de professores do ensino superior. Revista Triângulo. Uberaba, v. 8, n. 2, p. 04-13, jul./dez. 2015.

Professor universitário: um profissional da educação na atividade docente. In:

MASETTO, M. T. (Org.). Docência na universidade. 6. ed. Campinas: Papirus, 2003.

MELARÉ, D. et al. Educação e Tecnologias: reflexão, inovação e práticas. Lisboa, Portugal: Universidade Aberta, 2011.

MONTERO, M. L.; GEWERC, A. De la innovación deseada a la innovación posible. Escuelas alteradas por las TIC. Profesorado. Granada, v. 14 (1), p. 303-318, 2010. Disponível em: 〈http://www.ugr.es/local/recfpro/rev141ART16.pdf>.

MORAN, J. Formação de educadores inovadores para uma nova escola. In: TV ESCOLA Série Salto para o Futuro - Educação digital e tecnologias da informação e comunicação. Secretaria de Educação a Distância, Ministério da Educação, programa 3, ano XVIII, boletim 18, p. 40-48, 2008. Disponível em: 〈www.tvbrasil.org.br/salto〉. 
MUÑOZ-CANO, J. M.; CÓRDOVA, J. A.; PRIEGO, H. Dificultades y facilidades para el desarrollo de un proceso de innovación educativa con base en las Tecnologías de la Información y Comunicación (TIC). Formación Universitaria. Santiago, v. 5(1), p. 3-12, 2012.

OECD. TALIS 2013 Results: an international perspective on teaching and learning, OECD Publishing, Paris, 2014. Disponível em :<http://www.keepeek.com/Digital-AssetManagement/oecd/education/talis-2013-results_9789264196261-en\#page2>.

OLIVEIRA, A.; PRATA-LINHARES, M. M.; KARWOSKI, A. M.. Instituciones Federales de Educación Superior en Brasil y el desarrollo del profesor universitario. In: CONGRESO INTERNACIONAL DE EDUCACIÓN V, 2016, Caracas. Anais do V Congreso Internacional de Educación. Alternativas Pedagógicas para la Educación del Siglo XXI, Caracas, 2016. p. $1-10$.

OROZCO, G. ¿Podemos ser más creativos al pensar sobre cómo adoptar generalizadamente la innovación tecnológica en la educación? Una propuesta desde la comunicación. Matrize, Guadalajara, p. 209-216, out. 2007.

PAREDES, J. Innovación en los procesos de educación a lo largo de la vida. In: PAREDES, J.; HERRÁN, A. (Coords.). La práctica de la innovación educativa. Madrid: Editorial Síntesis, 2009, p. 207-234.

PAREDES, J.; GUITERT, M.; RUBIA, B. La innovación y la tecnología educativa como base de la formación inicial del profesorado para la renovación de la enseñanza. In: RELATEC - Revista Latinoamericana de Tecnología Educativa, Cárceres, v. 14(1), p. 101-114, 2015.

PRATA-LINHARES, M. M.; MASETTO, M. T. Educación superior e innovación curricular: resultados de una investigación interinstitucional en red. Semina - Ciências Sociais e Humanas. Londrina, v. 34, p. 99-108, 2013. http://dx.doi.org/10.5433/16790383.2013v34n1p99

RISTOFF, Dilvo. Os desafios da educação superior na Ibero-América: inovação, inclusão e qualidade. Avaliação, Sorocaba: v. 18, n. 3, p. 519-545, nov. 2013. Disponível em: $<$ http://www.scielo.br/scielo.php?script=sci_arttext\&pid=S1414$40772013000300002 \& \operatorname{lng}=$ pt\&nrm=iso>.

REIS, J. Inovação, TIC e sala de aula. Lisboa: Repositório da Universidade Católica Portuguesa, 2013. p. 1-18.

ROGERS, Everett M. Diffusion of innovations. New York: The Free Press of Glencoe, 1962.

ROIG, R. De la investigación al conocimiento: reflexiones en torno a la innovación para la mejora de conocimiento educativo actual. In: ROIG, R. (Dir.). Investigación e innovación en el conocimiento educativo actual. Alcoy: Ed. Marfil, 2008, p. 7-14.

RUBIA, B. Experiencias colaborativas universitarias apoyadas en e-learning. In: PAREDES, J.; HERRÁN, A. Cómo enseñar en el aula universitaria. Madrid: Ediciones Pirámide, 2010, p. 109-117. 
SALINAS, J. Innovación educativa y TIC en el ámbito universitario: Entornos institucionales, sociales y personales de aprendizaje. In: II CONGRESSO INTERNACIONAL DE EDUCACIÓN A DISTANCIA Y TIC, 2009. Lima, Peru, 2009, p. 1-10.

SANCHO, J. M. et al. Formación del profesorado en Tecnología Educativa: de cómo las realidades generan los mitos. RELATEC - Revista Latinoamericana de Tecnología Educativa, Cárceres, v. 14, n. 1, p. 17-30, 2015.

SOARES, S. R.; VIEIRA, F. Aprendizagem, ensino e desenvolvimento profissional docente na universidade: desafios, perspectivas e trajetórias de mudança. Revista da FAEEBA: Educação e Contemporaneidade. Salvador: v. 23, n. 41, p. 165-177, jan./jun. 2014.

TEJADA, José. Innovación didáctica y formación del profesorado. In: HERRÁN, A. \& PAREDES, J. (Coords.). Didáctica general. La práctica de la enseñanza en educación infantil, primaria y secundaria. Madrid: McGraw Hill, 2008. p. 311-332.

UNESCO. Conferência Mundial sobre Ensino Superior 2009. As Novas Dinâmicas do Ensino Superior e Pesquisas para a Mudança e o Desenvolvimento Social. (UNESCO, Paris, de 5 a 8 de julho de 2009). COMUNICADO (08 de julho de 2009). Disponível em: $<$ http://portal.mec.gov.br/index.php?option=com_docman\&view=download\&alias=4512conferencia-paris\&Itemid=30192>.

UNESCO. Position Paper on Education Post-2015, 2014. Disponível em: <http://unesdoc.unesco.org/images/0022/002273/227336E.pdf>.

VEIGA, Ilma Passos Alencastro. A aventura de formar professores. 2. ed. Campinas: Papirus, 2010.

VESPASIANO, Luce Mary. As tecnologias digitais da informação e comunicação na docência universitária nos cursos de administração e ciências contábeis. 2016. $179 \mathrm{f}$.

Dissertação (Mestrado em Educação) - Universidade Federal do Triângulo Mineiro, Uberaba, 2016.

ZABALZA, M. O ensino universitário, seu cenário e seus protagonistas. Tradução de Ernani Rosa. Porto Alegre: Artmed, 2004. 